\title{
KILOCYCLE RANGE INTERNAL FRICTION IN PLASTICALLY DEFORMED MgO SINGLE CRYSTALS
}

\author{
M. GABBAY, C. ESNOUF and G. FANTOZZI \\ Groupe d'Études de Métallurgie Physique et de Physique des Matériaux, \\ E. R. A. 463, Bât. 502, I. N. S. A., 69621 Villeurbanne Cedex, France
}

\begin{abstract}
Résumé. - Des mesures de frottement intérieur ont été effectuées sur des monocristaux de $\mathrm{MgO}$ déformés plastiquement, pour étudier le comportement dynamique des dislocations dans le domaine de température compris entre $77 \mathrm{~K}$ et $473 \mathrm{~K}$. Le spectre d'amortissement obtenu présente quatre pics situés vers $150 \mathrm{~K}, 210 \mathrm{~K}, 290 \mathrm{~K}, 420 \mathrm{~K}$. L'analyse des résultats montre que le pic à $150 \mathrm{~K}$ est probablement lié à une manifestation intrinsèque des dislocations, le pic à $290 \mathrm{~K}$ semble être dû au désancrage thermomécanique des lignes de dislocations, le pic à $420 \mathrm{~K}$ pourrait être attribué à une réorientation de défaut ponctuel. La reproductibilité aléatoire des résultats obtenus sur le pic à $210 \mathrm{~K}$ ne permet pas une analyse convenable.

Abstract. - Internal friction measurements were performed on plastically deformed $\mathrm{MgO}$ single crystals to investigate dynamic dislocation behaviour over the temperature range from $77 \mathrm{~K}$ to $473 \mathrm{~K}$. The damping spectrum presents four peaks situated at about $150 \mathrm{~K}, 210 \mathrm{~K}, 290 \mathrm{~K}, 420 \mathrm{~K}$. Analysis of results shows that the $150 \mathrm{~K}$ peak is probably linked to intrinsic dislocation manifestation, the $290 \mathrm{~K}$ peak seems to be due to thermomechanical unpinning of dislocation lines, the $420 \mathrm{~K}$ peak should be attributed to point defect reorientation. No reproducible results for the $210 \mathrm{~K}$ peak do not allow a suitable analysis.
\end{abstract}

1. Introduction. - Extensive studies have been carried out on dislocation dynamics and thermally activated deformation of $\mathrm{MgO}$ single crystals in the low temperature range [1-5]. From the analysis of results, the most probable rate controlling mechanisms are :

(i) the Peierls Nabarro lattice resistance mechanism,

(ii) the dislocation-impurity atom interaction.

Singh and Coble [4] suggested that dislocation mobility in pure $\mathrm{MgO}$ single crystals $(<20$ p.p.m. Fe impurity) depends on the state of ionization of iron impurities :

- in the reduced state $\left(\mathrm{Fe}^{2+}\right)$, the dislocation motion is controlled by the Peierls-Nabarro mechanism ;

- in the oxidized state $\left(\mathrm{Fe}^{3+}\right)$, the dislocation mobility can be attributed both to the Peierls-Nabarro mechanism and to the dislocation-impurity atom interaction.

In less purer $\mathrm{MgO}$ single crystals ( $>50$ p.p.m. Fe impurity) the dislocation-impurity atom interaction seems to be the predominant rate controlling mechanism $[1,2,3,5]$. The aim of the present investigation is to study the mechanisms controlling the dynamic dislocation behaviour using internal friction method.

If the Peierls-Nabarro stress is high enough, an internal friction peak due to the thermally activated double kink formation (Bordoni peak) is expected [6, 7]. The activation energy of this peak must be equal to the activation barrier obtained from the analysis of dynamic dislocation behaviour [4]. It is also possible that the kink potential barrier is large enough to give rise to a relaxation peak due to the lateral motion of geometrical kinks [6, 7, 8]. Finally, when the dislocation-point defect interaction controls the dislocation mobility, it should be possible to observe anelastic manifestations due to this interaction (thermally activated break-away peak or Hasiguti peak) $[9,10]$.

A small number of studies have been carried out on $\mathrm{MgO}$ single crystals using internal friction measurements $[11,12,13,14,15,16]$. Damping measurements over kilocycle range were performed by Southgate et al. [15] ; however, their results do not show clearly the forseeable preceding anelastic manifestations.

2. Experimental procedure. - 2.1 SAMPLES. Single crystals of magnesium oxide were obtained from the Norton Company which cleaved specimens along $\{100\}$ faces to their final dimensions of approximately $40 \times 4 \times 2 \mathrm{~mm}^{3}$. The chemical analysis furnished by the Norton Company is given in following table :

$\begin{array}{llllllll}\mathrm{SiO}_{2} & \mathrm{Fe}_{2} \mathrm{O}_{3} & \mathrm{TiO}_{2} & \mathrm{Al}_{2} \mathrm{O}_{3} & \mathrm{CaO} & \mathrm{ZrO}_{2} & \mathrm{MnO}_{2} & \mathrm{NiO} \\ 30 \overline{\mathrm{ppm}} & \frac{\mathrm{140}}{12} & \frac{\overline{44}}{30} & \frac{14}{25} & \frac{5}{5}\end{array}$

2.2 SPECIMENS PREPARATION. - The specimens were chemically polished in hot orthophosphoric acid to 
remove surface damage due to cleavage and machining. Then they were annealed at $1250^{\circ} \mathrm{C}$ for 24 hours and air-quenched to room temperature in view to obtain uniform impurity distribution. In addition, this treatment stabilized iron impurities in the trivalent state [4]. Specimens were coated with a very thin metallic film needed for electrostatic excitation of vibrations. Plastic deformation was performed by compression along the [100] axis at room temperature, using an Instron machine at a base strain rate of $2 \times 10^{-5} \mathrm{~s}^{-1}$.

2.3 Apparatus. - We have designed an apparatus for automatic measurement of internal friction and modulus using a vibrating sample in flexural mode [17]. An excitation-detection electrode is located in front of the middle of the specimen fixed at its nodal points by fine nickel wires. This configuration allows an electrostatic excitation and a frequency modulation detection (Fig. 1). Logarithmic decrement is measured

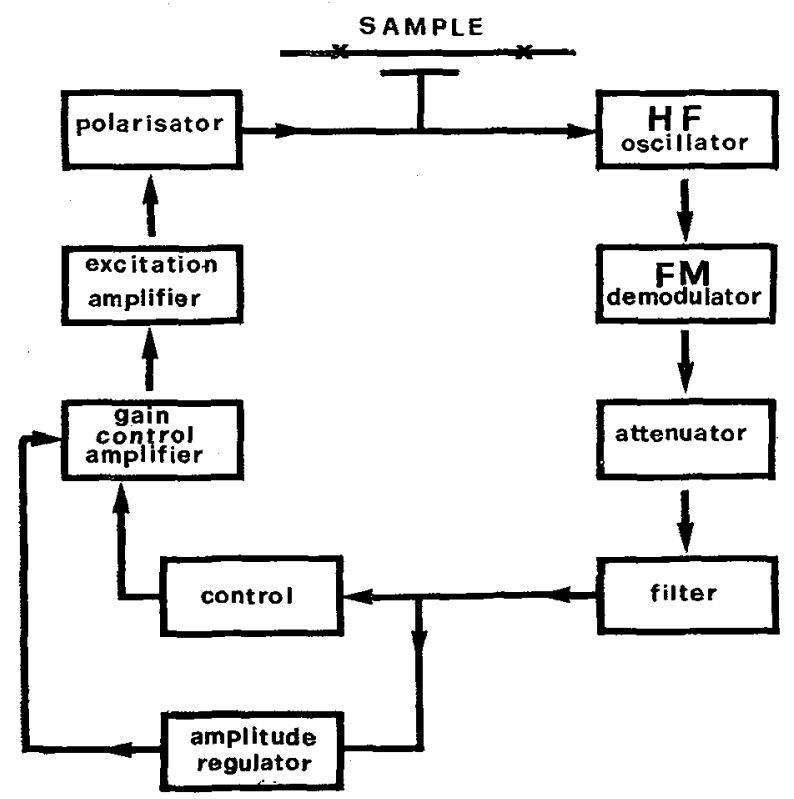

FIG. 1. - Schematic diagram for excitation-detection electronic system.

during periodic free decay by an electronic counter. Internal friction and vibration frequency measurements are recorded :

- either as a function of temperature (from $77 \mathrm{~K}$ to $873 \mathrm{~K}$ ) at a constant vibration amplitude during linear heating at a rate of $30 \mathrm{~K} / \mathrm{h}$.

- or as a function of vibration amplitude $\varepsilon$ (over $10^{-8}$ to $10^{-4}$ range) at a constant temperature.

3. Experimental results. - Figure 2 shows the internal friction as a function of temperature as measured on a sample lightly cold-worked $(<1 \%)$ at room temperature. The measurements were performed at about $10 \mathrm{kHz}$ and at constant strain amplitude of $5 \times 10^{-6}$. Directly after cold-work, four

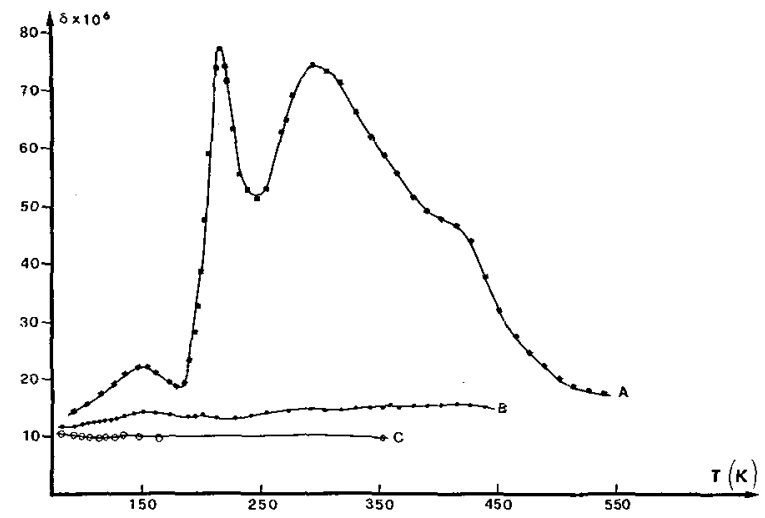

FIG. 2. - Logarithmic decrement as afunction of temperature for a lightly cold-worked sample : A) after cold-work; B) after annealing at $600 \mathrm{~K}$; C) after annealing at $900 \mathrm{~K}$.

peaks are observed at different temperatures : $150 \mathrm{~K}$, $210 \mathrm{~K}, 290 \mathrm{~K}, 420 \mathrm{~K}$. These different peaks will be called $150 \mathrm{~K}, 210 \mathrm{~K}, 290 \mathrm{~K}, 420 \mathrm{~K}$ peaks even if an eventual temperature shift becomes. After annealing at $600 \mathrm{~K}$, general decreasing of internal friction is observed from $77 \mathrm{~K}$ to $473 \mathrm{~K}$ with an important smoothing of the peaks. After another annealing a $900 \mathrm{~K}$, a flat curve is obtained with a little background less than $10^{-5}$.

Then, with a new plastic deformation (about $1 \%$ ), reappearance of the $150 \mathrm{~K}, 210 \mathrm{~K}$ and $290 \mathrm{~K}$ peaks is observed and higher background is noticed (figure 3 curve $\mathrm{A}$ ). The $150 \mathrm{~K}$ peak is higher than after the first deformation while the $210 \mathrm{~K}$ and $290 \mathrm{~K}$ peaks are smaller. Annealing effects on the internal friction spectrum are shown by the curves $B$ and $C$ (Fig. 3):

- decreasing of the peak height,

- peak temperature deviation (towards lower temperature for the $150 \mathrm{~K}$ peak and towards higher temperature for the $210 \mathrm{~K}$ peak).

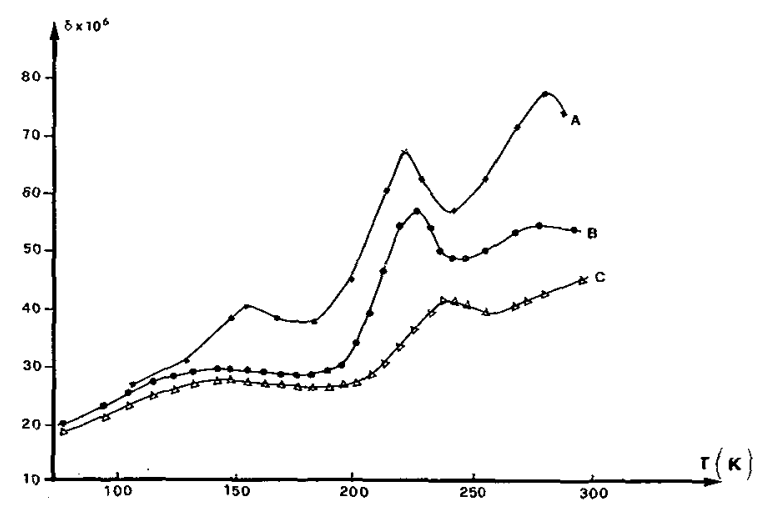

FIG, 3. - Effect of new plastic deformation (about $1 \%$ ) on the internal friction spectrum measured at constant vibration amplitude of $5 \times 10^{-6}:$ A) after deformation; B) after heating at $330 \mathrm{~K}$; C) after annealing at $350 \mathrm{~K}$ during 12 hours.

We have performed similar experiments with another set of samples coming from a new delivery.

Figure 4 presents the internal friction versus tem- 


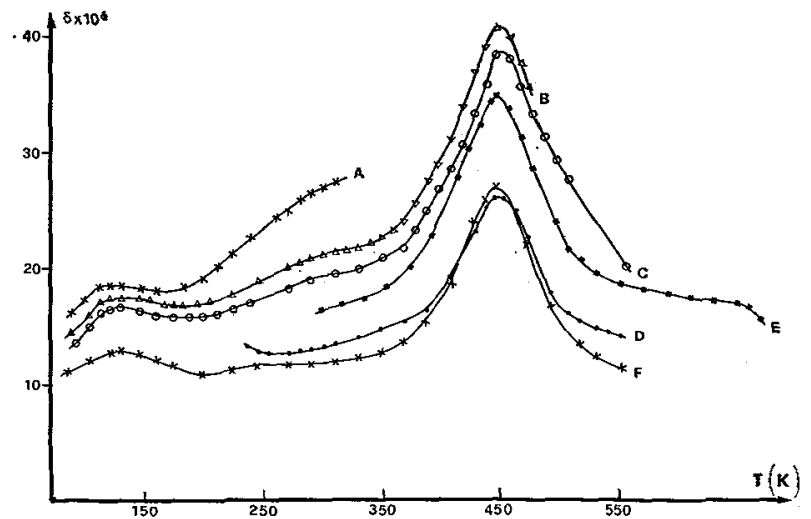

FIG. 4. - Internal friction spectrum for a lightly cold-worked sample (another set): A) after deformation $\left(\varepsilon=5 \times 10^{-6}\right)$; B) after heating up to $310 \mathrm{~K}\left(\varepsilon=5 \times 10^{-6}\right)$; C) after heating up to $\left.473 \mathrm{~K},\left(\varepsilon=5 \times 10^{-6}\right) ; \mathrm{D}\right)$ after heating up to $560 \mathrm{~K}$ $\left(\varepsilon=3 \times 10^{-7}\right) ;$ E) idem $\left(\varepsilon=5 \times 10^{-6}\right) ;$ F) after heating up to $673 \mathrm{~K}\left(\varepsilon=5 \times 10^{-6}\right)$.

perature plots for these samples lightly cold-worked. Only two peaks ( $150 \mathrm{~K}$ and $420 \mathrm{~K}$ ) appear with a slight shift towards lower and higher temperatures respectively. Between $220 \mathrm{~K}$ and $330 \mathrm{~K}$ a smooth bump seems to be present. Temperatures and heights of these two peaks are a little affected by different temperatures annealing and by strain amplitude of vibration. Only internal friction background is essentially modified.

Internal friction spectrum is also modified by higher plastic deformation $(4 \%)$ as we can see in

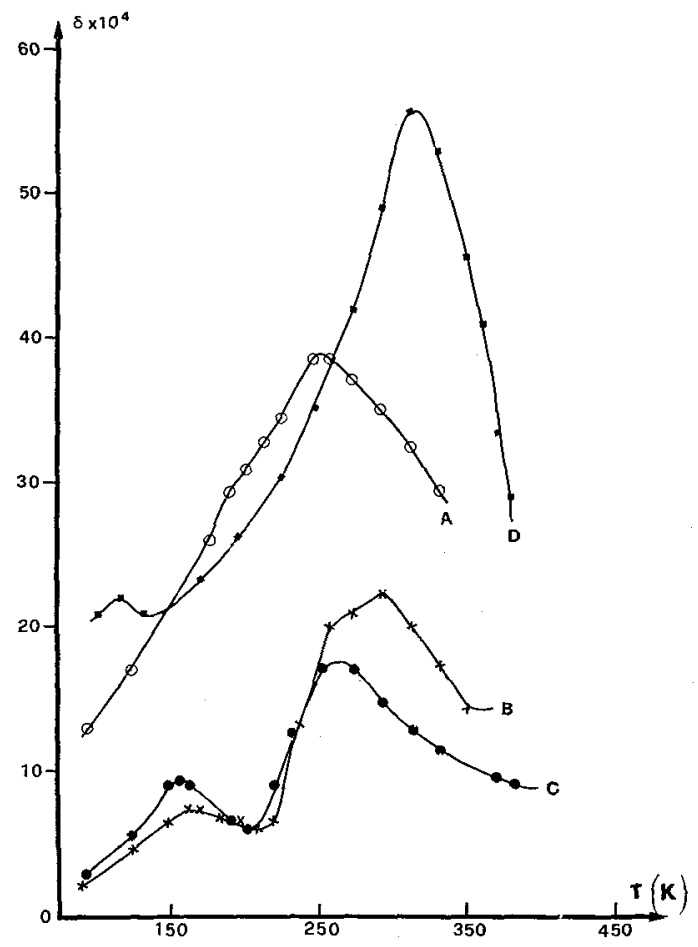

FIG. 5. - Internal friction as a function of temperature for a heavily coldworked sample $(4 \%):$ A) after plastic deformation and heating up to $\left.330 \mathrm{~K}\left(\varepsilon=5 \times 10^{-6}\right) ; \mathrm{B}\right)$ after heating up to $\left.330 \mathrm{~K}\left(\varepsilon=2.5 \times 10^{-7}\right) ; \mathrm{C}\right)$ idem $\left(\varepsilon=1.5 \times 10^{-7}\right)$; D) after heating up to $400 \mathrm{~K}\left(\varepsilon=1.5 \times 10^{-5}\right)$. figure 5. Considerable increasing of internal friction takes place. With small vibration amplitude, two peaks are clearly observed : the $150 \mathrm{~K}$ peak and the $290 \mathrm{~K}$ (curves B and C Fig. 5). With high strain amplitude (curves A and D Fig. 5), a large increase of internal friction is noticed in the whole range of temperature, the $150 \mathrm{~K}$ peak being masked. The magnitude and the temperature of the $290 \mathrm{~K}$ peak is strongly affected by annealing conditions and by strain amplitude of vibration.

4. Discussion. - 4.1. $150 \mathrm{~K}$ PEAK. - With attenuation measurements of internal friction, Chang [11] and Ikushima and Suzuki [13] have found a peak near $270 \mathrm{~K}$ at about $50 \mathrm{MHz}$. An extrapolation of their results lead to a temperature peak of $130 \mathrm{~K}$ for a vibration frequency of $10 \mathrm{kHz}$ (figure 6). This value falls in approximately with the $150 \mathrm{~K}$ peak temperature we obtain. Thus, we may think that the nature of $150 \mathrm{~K}$ peak is the same of the peak observed by Chang and Ikushima and Suzuki. The activation energy $E$ and the attempt frequency $f_{0}$ are deduced from the whole results :

$$
E=0.22 \pm 0.03 \mathrm{eV}
$$

and

$$
10^{11}<f_{0}<6 \times 10^{12} \mathrm{~s}^{-1} \text {. }
$$

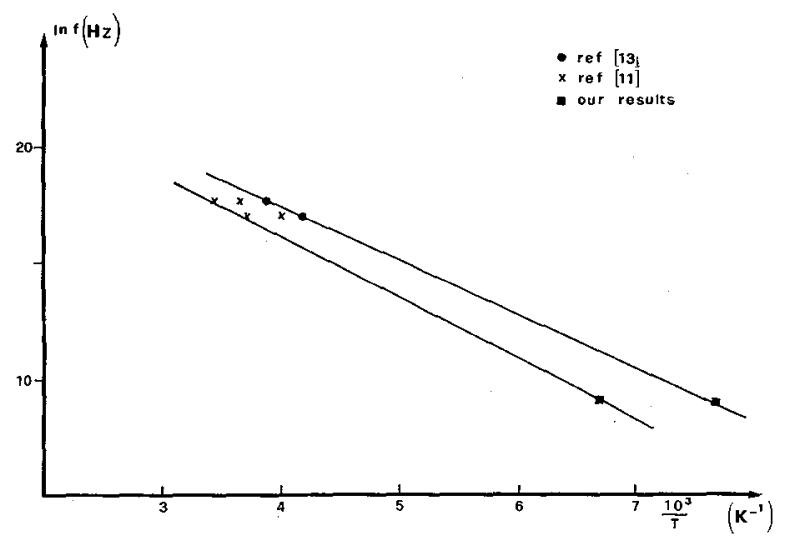

Fig. 6. - Arrhenius plot of peak temperature at different frequencies.

This activation energy value is lower than the activation barrier for the Peierls mechanism determined by Singh and Coble [4] (respectively $0.46 \mathrm{eV}$ and $0.71 \mathrm{eV}$ for edge and screw dislocations). Consequently, it is not possible to identify the $150 \mathrm{~K}$ peak to a Bordoni peak. The features of the $150 \mathrm{~K}$ peak are :

- the peak height increases with increasing amounts of cold work and decreases lightly by annealing at low vibration amplitude (figure 4 and figure 5); - the relaxation peak is a little sensitive to the strain amplitude below a critical vibration amplitude from which the background increases rapidly and masks the peak ; 
- the peak temperature is slightly affected by annealing, strain amplitude of vibration and amount of cold-work.

These features suggest that the $150 \mathrm{~K}$ peak is probably linked to an intrinsic dislocation manifestation and it is proposed that the relaxation is due to the lateral motion of geometrical kinks. This hypothesis would have to be confirmed by new esperiments.

$4.2210 \mathrm{~K}$ PEAK. - This peak has been observed only with the first set of specimens. The peak height is very sensitive to annealing temperature above room temperature (Fig. 2 and 3 ) ; it disappears by heating up to $600 \mathrm{~K}$. By a new cold-work, one gets again the peak, however with smaller height (Fig. 2 and 3). These results do not allow to propose a reasonable mechanism hypothesis.

4.3 $290 \mathrm{~K}$ PEAK. - In this temperature range, the internal friction is very sensitive to the strain amplitude (Fig. 5). We observe that the peak temperature and height vary greatly with the annealing conditions and the vibration amplitude. The effect of strain amplitude on the internal friction at room temperature for the heavily cold-worked samples ( $4 \%$ ) after heating up to $400 \mathrm{~K}$ is shown by the figure 7 . We notice that the internal friction goes through a maximum as a function of strain amplitude. This amplitude dependent damping can be associated to an unpinning of dislocations (Granato and Lücke model [18]). Furthermore, the damping exhibits an hysteresis when the measurements are carried out with the amplitude decreasing (Fig. 7), the maximum of the internal friction taking place at a strain amplitude lower than the one at which the maximum occurs during the amplitude increasing. This result indicates pinning agent mobility [10]. Thus it is reasonable to attribute the $290 \mathrm{~K}$ peak to the thermomechanical unpinning of dislocation lines; we may suggest that the pinning points are the impurityvacancy dipoles which seem to control the thermally activated deformation $[2,3,4]$.

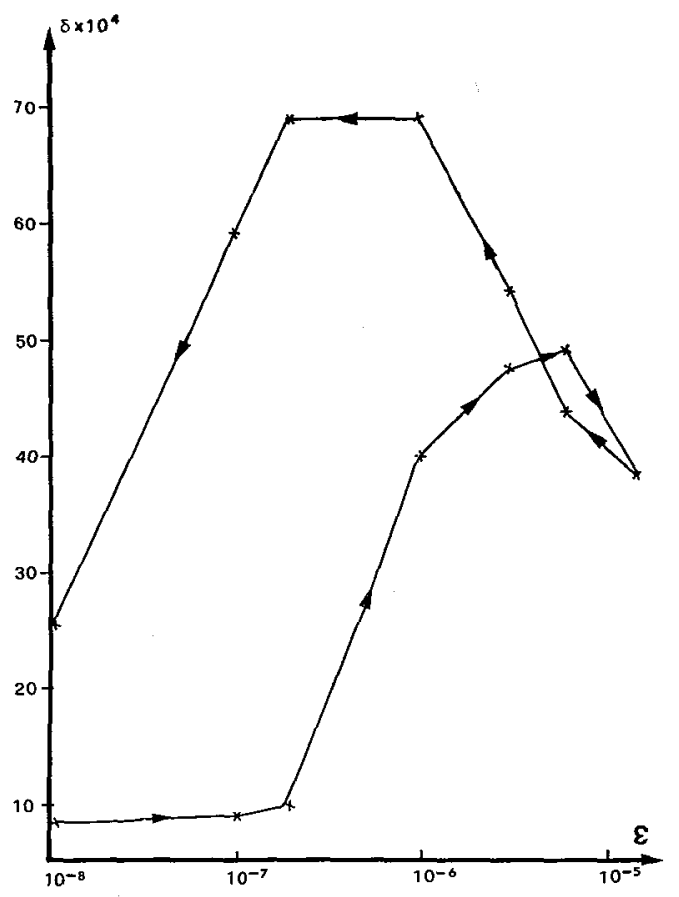

FIG. 7. - Variation of internal friction with strain amplitude $\varepsilon$ at room temperature in the heavily cold-worked sample $(4 \%)$ after heating up to $400 \mathrm{~K}$.

4.4 420 K PEAK. - This peak is the same that the one obtained by Southgate [14]. It appears in the annealed state and remains after low plastic deformation. Southgate has shown that this peak is due to a defect reorientation of a center which has a [100] symmetry.

In conclusion, these results constitute the first exploratory step of our investigation on dynamic dislocation behaviour in $\mathrm{MgO}$ single crystals. Each of the anelastic manifestations which occur along the internal friction spectrum, needs more experiments to try and precise the responsible mechanisms of dislocation motion.

\section{References}

[1] Srinivasan, M., Stoebe, T. G., J. Mat. Sci. 8 (1973) 1567.

[2] Srinivasan, M., Stoebe, T. G., J. Mat. Sci. 9 (1974) 121.

[3] Sinha, M. N., Lloyd, D. J., TANGRI, K., Phil. Mag. 28 (1973) 1341.

[4] Singh, R. N., Coble, R. L., J. Appl. Phys. 45 (1974) 981.

[5] Singh, R. N., Coble, R. L., J. Appl. Phys. 45 (1974) 990.

[6] SeEger, A., J. Physique Colloq. 32 (1971) C2-193.

[7] Benort, W., Fantozzr, G., Esnouf, C., Nuovo Cimento 33B (1976) 1.

[8] WÜTHRICH, C., Script. Met. 9 (1975) 641.

[9] LÜCKE, K., SCHLIPF, J., The Interactions between Dislocations and Point Defects, edited by B. L. Eyre, Harwell, 1968, 118.
[10] Perez, J., Peguin, P., Fantozzi, G., Gobin, P., Ann. Phys. 5 (1970) 303.

[11] Chang, R., J. Appl. Phys. 32 (1961) 1127.

[12] DahlberG, P., Carnahan, R. D., Brit́tain, J. O., $J$. Appl. Phys. 33 (1962) 3493.

[13] Ixushima, A., Suzuki, T., J. Phys. Soc. Japan 18 (1963), Suppl. I, 163.

[14] Southgate, P. D., J. Appl. Phys. 36 (1965) 2696.

[15] Southgate, P. D., Mendelson, K. S., Deperro, P. L., J. Appl. Phys. 37 (1966) 206.

[16] Ritchie, I. G., Sprungmann, K. W., Script. Met. 7 (1973) 323.

[17] Secretan, B., Thesis, Ecole Polytechnique fédérale de Lausanne.

[18] Granato, A., Lücke, K., J. Appl. Phys. 27 (1956) 583. 


\section{DISCUSSION}

M. P. Puls. - 1) Could you tell me, first of all, what the purity of your crystal was ?

2) I would like to make a comment regarding your speculation whether one of your peaks corresponds to a Bordoni relaxation. Using our atomistic model for an edge dislocation in $\mathrm{MgO}$ we have been able to calculate the complete peierls-energy barrier. Using this result and the model of Guyot and Dorn, we have calculated the double kink formation energy. Our calculations indicate that considering the low applied stresses and the high impurity content (particularly $\mathrm{Fe}^{3+}$ ions), it is unlikely that the Bordoni relaxation would be operative.

M. GabBay. - 1) The delailed chemical analysis is included in our paper. The total content of impurities is less than 300 p.p.m., the Fe impurity content of which is less than 150 p.p.m.

2) We are in a complete agreement with your comment as we have said in our discussion. 